\title{
UM MODELO DE APRESENTAÇÃO DE ANÁLISE FUNCIONAIS DO COMPORTAMENTO ${ }^{1}$
}

\author{
A MODEL FOR PRESENTATION OF FUNCTIONAL \\ ANALYSIS OF BEHAVIOR
}

\author{
Silvana Elisa Gonçalves de Campos $\operatorname{COSTA}^{1}$ \\ Maria Luiza MARINHO²
}

\begin{abstract}
RESUMO
O termo análise funcional é empregado inúmeras vezes por analistas do comportamento durante atividades científicas, didáticas, da prática clínica e outras, como método adotado para o estabelecimento de relações entre variáveis e comportamento. A forma de apresentação das análises funcionais pode facilitar ou dificultar a compreensão da mesma. O principal objetivo do presente artigo é mostrar um modelo de apresentação de análises funcionais que procura ser simples, claro e conciso, de forma que tanto alunos como terapeutas principiantes possam compreender as análises propostas e apresentar análises funcionais seguindo o mesmo formato. Como demonstração, serão apresentadas análises funcionais de comportamentos de uma jovem que procurou os serviços de psicologia da clínica-escola da Universidade Estadual de Londrina.
\end{abstract}

Palavras-chave: Análise funcional, behaviorismo radical, análise do comportamento.

\begin{abstract}
The term functional analysis is used a lot of times by behavior' analysts during scientific, didactic, clinical and other activities as the method

\footnotetext{
(1) Monografia apresentada pela primeira autora ao Curso de Especialização em Psicoterapia na Análise do Comportamento, da Universidade Estadual de Londrina, sob supervisão da segunda autora.

(2) Endereço para correspondência: Maria Luiza Marinho, Universidade Estadual de Londrina, Dept ${ }^{\circ}$ de Psicologia Geral e Análise do Comportamento, Caixa Postal 6001, 86051-990, Londrina - PR. E-mail: apicsabrasil@onda.com.br Fone/Fax: 0XX43 3385476.realizada pela segunda autora, sob orientação da primeira como exigência do curso de Especialização em Análise do Comportamento da Universidade Estadual de Londrina.
} 


\begin{abstract}
adopted for the establishment of relationships between variables and behavior. The form of presentation of functional analysis could facilitate or difficult the understanding of these analysis. The main goal of this article is to show a model of presentation of functional analysis that looks simple, clear and concise. The specific purpose is to facilitate that not only students but also naive therapists can understand the proposed analysis and present functional analysis based on the same format. As a demonstration, the functional analysis of a youth's behaviors referred to the services of the psychological clinic of the State University of Londrina will be presented.
\end{abstract}

Key-words: Functional analysis, radical behaviorism, behavior analysis

O termo Análise Funcional é empregado inúmeras vezes por analistas do comportamento durante atividades científicas, didáticas e de prática clínica. Dada a sua ampla utilização, o presente artigo tem como objetivo realizar uma breve caracterização desse método e apresentar um modelo de apresentação de análises funcionais que procura ser simples, claro e conciso, exemplificado com comportamentos de uma jovem que procurou os serviços de psicologia da clínica-escola da Universidade Estadual de Londrina.

\section{ANÁLISE FUNCIONAL COMO MÉTODO PARA COMPREENSÃO DO COMPORTAMENTO}

Segundo Carr, Langdon e Yarbrough (2000), o behaviorismo operante é, essencialmente, a análise científica das intenções, motivações, objetivos e propósitos. No entanto, seguindo os pressupostos filosóficos e epistemológicos do Behaviorismo Radical, comportamentalistas operantes evitam utilizar termos mentalistas como "propósito" ou afins como "intenção", "motivação" e "objetivo". Em seu lugar, optam por falar de variáveis das quais o comportamento é função e o nome que se dá ao método para identificar essas variáveis é "análise funcional".

Haynes e O’Brien (1990) definem análise funcional como "a identificação de relações relevantes, controláveis, causais e funcionais aplicáveis a um conjunto específico de comportamentos-alvo para um cliente individual" (p.654). Assim, embora um problema clínico possa ser relatado por um indivíduo, um grupo ou uma organização, em qualquer destes casos, o procedimento é o mesmo: decidir a qual informação coletar, delinear o problema, decidir que ações proceder e avaliar as mudanças.

Considerando-se que análises funcionais possam ser realizadas não somente de forma restrita a comportamentos de indivíduos, Gresswell e Hollin (1992) fazem distinção entre análise funcional idiográfica (a análise de casos individuais, objeto de estudo do presente artigo) e nomotética (análise funcional de uma categoria diagnóstica, como o exemplo clássico de análise funcional da depressão, publicada por Ferster em 1973). A essas duas categorias, Sturmey (1996) adiciona outras duas: análise funcional de processos psicológicos (como imitação, desenvolvimento infantil, entre outros) e análise funcional de sistemas complexos (como organizações, ambiente terapêutico, prisões).

O principal instrumento conceitual adotado para a realização de análises funcionais é o conceito de contingência, introduzido por Skinner em 1938, e que aparece depois como central em toda a sua obra:

"Uma formulação das interações entre um organismo e o seu meio ambiente, para ser adequada, deve sempre 
especificar três coisas: 1) a ocasião na qual ocorreu a resposta, 2) a própria resposta e 3) as conseqüências reforçadoras. As relações entre elas constituem as 'contingências de reforço'" (Skinner, 1975, p.182).

"é apenas quando analisamos o comportamento sob contingências conhecidas de reforço que podemos começar a ver o que ocorre na vida cotidiana. Fatos que inicialmente desprezamos começam a comandar a nossa atenção, e coisas que inicialmente nos chamavam a atenção aprendemos a descontá-las ou ignorá-las. (...) Em outros termos, não mais encaramos o comportamento e o ambiente como coisas ou eventos separados, mas nos preocupamos com a sua inter-relação. Procuramos as contingências de reforço. Podemos então interpretar o comportamento com mais sucesso" (Skinner, 1975, p.184).

Interpretar um comportamento significa compreender sua função, que pode variar de um indivíduo a outro, entre situações e no tempo. De forma geral, as funções dizem respeito à obtenção de estímulos apetitivos (ou prazerosos) ou á evitação de estímulos aversivos. Pesquisas são conduzidas de forma a especificar, de modo genérico, as funções de condutas que tendem a ocorrer dados determinados contextos.

Como comentado acima, o método para se buscar compreender um comportamento (a chamada análise funcional), passa pelo estabelecimento de relações entre variáveis funcionais. Segundo Haynes e O'Brien (1990), algumas variáveis funcionais são causais, outras correlacionais; algumas são controláveis ou modificáveis, outras não; algumas são importantes em magnitude, enquanto outras são triviais. O papel do analista do comportamento é, justamente, indicar as relações existentes entre tais variáveis e o comportamento em questão.
Em relação às análises funcionais, os autores (Haynes e O'Brien, 1990) destacam, ainda, as seguintes características:

a) são mais probabilísticas que deterministas;

b) são transitórias e podem variar com o tempo (por exemplo, as variáveis relacionadas ao início de um problema podem não ser aquelas relacionadas a seu desenvolvimento posterior ou manutenção atual);

c) são não-excludentes, ou seja, a relação entre duas variáveis não impede a relação entre essas e outras variáveis;

d) variáveis funcionais podem ser de nível macro (como etnia ou classe social) ou variáveis de nível micro (como freqüência de criticismo social);

e) relações funcionais causais requerem que as variáveis causais sempre precedam o evento causado; esta é uma condição necessária, mas não suficiente para causalidade;

f) eventos privados podem entrar na análise funcional em diferentes vias: podem ser o comportamento-alvo, podem ser antecedentes ou podem ser conseqüências;

g) identificar as variáveis que atualmente causam um problema clínico pode ser muito difícil, já que no ambiente natural há muitas outras variáveis que estão correlacionadas com a causa verdadeira;

h) podem ter limites; uma importante limitação é que relações funcionais são difíceis de serem comprovadas.

Em adição ao apresentado até o momento sobre o tema, é importante destacar que há autores (Carr, Langdon e Yarbrough, 2000; Iwata, Vollmer e Zarcone, 1990; Baer, Wolf e Risley, 1968; Skinner, 1953) que, sensíveis ao problema de que relações funcionais entre variáveis podem ser mais aparentes que reais, restringem o termo análise funcional à manipulação experimental de variáveis para demonstrar relações causais 
entre variável independente e comportamento. Segundo esses autores, abordagens não-experimentais podem gerar hipóteses, mas não se pode dizer que constituem uma análise funcional enquanto a hipótese não for testada.

\section{ANÁLISE FUNCIONAL NA PRÁTICA CLÍNICA}

Quando se vai proceder à analise funcional de um comportamento, de todas as informações que se tem sobre a vida atual e passada do indivíduo, tem-se que selecionar aquelas variáveis que parecem ter relação causal com o comportamento analisado e, na verdade, somente se tem certeza da escolha das variáveis corretas após sua manipulação (em geral, durante a processo de intervenção). Num primeiro momento as relações estabelecidas são meramente hipotéticas.

Segundo Sturmey (1996), algumas análises funcionais são feitas mais minuciosamente na perspectiva da análise comportamental aplicada, em que o comportamento do indivíduo deve ser adequadamente descrito em termos seguramente operacionalizados. Além de especificar o comportamento-alvo, uma análise funcional adequada deve:

a) especificar os comportamentos substitutos tomados durante a intervenção, ou seja, os comportamentos adaptativos que podem ser efetivos em servir àquela mesma função;

b) especificar em termos funcionais as conseqüências que mantêm o comportamento problema (podem incluir tanto reforço positivo como negativo);

c) especificar as contingências que têm falhado em manter a resposta adaptativa (pode ser que a pessoa nunca tenha aprendido comportamento apropriado; que o comportamento apropriado tenha uma frágil história de aprendizagem; ou que atualmente haja pouco reforço ou haja punição para a resposta adaptativa).

Assim, a aplicação clínica da análise funcional não visa descrever todas as relações entre variáveis relevantes. Aquelas que apresentam magnitude insignificante e aquelas que não podem ser modificadas são excluídas para simplificar o quadro e para identificar aquelas variáveis que poderiam ser modificadas durante o tratamento. Nesse contexto, análise funcional é uma forma idiográfica de avaliação que é orientada ao desenvolvimento de um tratamento adaptado individualmente (Sturmey, 1996). Pode, inclusive, ser vista como tratamento em si mesma ou como um componente deste (por exemplo, autores como Goldiamond, 1975, recomendam que clientes devam ser incentivados a descobrir sua própria análise funcional ao invés de recebê-la pronta do terapeuta).

\section{UM MODELO DE APRESENTAÇÃO DE ANÁLISES FUNCIONAIS}

Para os analistas do comportamento, independentemente de onde desenvolvam sua atividade e de qual seja ela (ensino, pesquisa, extensão, administração, prática clínica, etc.), a análise funcional ocupa um ponto central. Embora pareça de menor importância, a forma de apresentação pode contribuir para facilitar ou dificultar a compreensão da análise funcional proposta. Algumas formas esquemáticas de apresentação ocasionalmente geram confusão devido às inúmeras setas, níveis e direções em que se deve seguir a leitura do esquema.

O modelo apresentado abaixo visa manter a concisão de formas esquemáticas de apresentação de dados, mas com certa clareza e simplicidade, de modo a possibilitar que mesmo alunos e terapeutas principiantes possam compreender a análise proposta e 
apresentar análises funcionais seguindo o mesmo formato.

A seguir será descrito o caso de uma jovem que procurou a clínica-escola da Universidade Estadual de Londrina para atendimento psicológico. Primeiramente, serão apresentadas as principais informações relacionadas ao caso e, em seguida, as relações funcionais de alguns comportamentos apresentados pela cliente. Não se pretende, aqui, apresentar a análise de todos os comportamentos clinicamente relevantes, mas daqueles que pareceram ser mais ilustrativos ao leitor para demonstrar análises funcionais, apresentadas sob a forma de contingências de três termos (antecedentes, comportamento e conseqüências).

\section{Descrição do Caso ${ }^{1}$}

A cliente, a qual chamaremos Ana, é do sexo feminino, 27 anos de idade na época da avaliação, segundo grau completo e nível sócioeconômico médio; trabalhava como técnica de laboratório. Estava casada há dois anos e a queixa apresentada foi depressão. Procurou a clínica psicológica encaminhada pelo psiquiatra com quem fazia tratamento há um ano, período durante o qual vinha tomando antidepressivo. Filha mais velha da família, tinha uma irmã e um irmão, ambos também casados. O relacionamento com o pai, segundo ela, sempre fora difícil. Na adolescência, ele a expulsara de casa, alegando que não aceitava que ela saísse à noite com amigos. Por isso, Ana morou por dois anos com a avó em outra cidade. Sua mãe, segundo a cliente, nunca tomou nenhuma iniciativa em relação às atitudes do pai. Quando voltou a morar com os pais, Ana passou a freqüentar um grupo de estudos bíblicos da religião Testemunhas de Jeová e fez várias amizades. Permaneceu nesse grupo por cinco anos e relatou que nesse período sentia-se muito bem. Considerava que o ideal seria casar-se com alguém do grupo; porém, envolveu-se com um rapaz que conheceu no trabalho e se casaram. O marido era da religião Católica e nunca participou das atividades da religião de Ana. Após casar-se, Ana foi reduzindo sua participação nas reuniões do grupo, até que parou de freqüentá-las totalmente. Também, logo após seu matrimônio, ocorreu o falecimento de sua avó.

São apresentadas, a seguir, as principais informações obtidas nas sessões iniciais de avaliação, com alguns comentários sobre seu possível efeito em alguns comportamentos (públicos e privados) apresentados por Ana.

a) As queixas apresentadas por Ana ao início da terapia foram: desânimo, cansaço, dores no corpo, dificuldades para enfrentar os problemas do dia-a-dia e em fazer amizades, vontade de fugire de dormir e elevada sensibilidade diante de acontecimentos ruins. Relatou desejo de mudar esse seu jeito de ser.

b) A cliente relatou que devido às dores no corpo, não conseguia fazer os serviços de casa e, por isso, contava com a ajuda de sua mãe e de seu marido: ontem, eu cheguei em casa e fui direto deitar. Tinha um monte de coisas para fazer. Meu marido é que foi arrumar as coisas para mim. Quando levantei, tomei banho, jantei e deitei de novo.

c) Observou-se que Ana contava com um número reduzido de pessoas significativas em sua vida. A respeito disso, relatou que tinha apenas uma amiga íntima e acrescentou: ela (a avó) era a pessoa que mais me dava carinho. Meu pai e minha mãe nunca

(1) O caso é parte da monografia realizada pela segunda autora, sob orientação da primeira como exigência do curso de Especialização em Análise do Comportamento da Universidade Estadual de Londrina. 
foram muito carinhosos e ela era. Ela me faz tanta falta! Se eu perder meu marido, em matéria de amor, eu não vou ter mais.

d) A cliente apresentava verbalizações que indicavam sentir-se inferior às demais pessoas: (...) meu marido já vai terminar o mestrado, fazer doutorado e eu não fiz nem a graduação. Uma hora ele vai conhecer uma pessoa mais interessante, mais inteligente, mais estudiosa.

e) Com o casamento, Ana pareceu estar em situação de conflito: consolidar a escolha entre freqüentar o grupo bíblico sem o marido ou acompanhá-lo em suas reuniões sociais que lhe eram aversivas. Sobre isso, comentou:

Eu fico nas festas, no meio daquelas pessoas bebendo, me dá uma coisa tão ruim! Parece que não era ali que eu queria estar; eu queria estar com meus amigos de lá (do grupo religioso), que não bebem e nem fumam, não contam piada obscena. (...) Quando eu estava lá (no grupo religioso), eu sentia muita falta de alguém. (...) E agora eu tenho ele, meu marido, mas não tenho o ambiente que eu gostava, não tenho os amigos.

f) Parece que as expectativas de Ana em relação ao casamento não foram satisfeitas, principalmente nos primeiros dois anos. Segundo ela, o marido não demonstrava afeto, não ficava em casa a quantidade de tempo que ela gostaria, não tinham em sua rotina realizar atividades conjuntas. Além disso, o marido continuou a manter a vida social que tinha quando solteiro, com festas nos fins de semana e encontros em bares para beber e conversar durante a semana.

g) Ana sofreu o que foi diagnosticado por um psiquiatra como uma forte crise depressiva no final do primeiro ano de casamento. Nesse período, ela tinha idéias de suicídio, não queria sair de casa e chorava freqüentemente: eu me tranquei no banheiro uma vez, sentei no chão e comecei a chorar, chorar, chorar e ele (marido) arrebentou a porta.

h) Observou-se que a cliente, em geral, sentia-se inadequada em diversas situações, além de, às vezes, comportar-se inassertivamente. Ela, freqüentemente, deixava de dar sua opinião, tinha medo de magoar as pessoas e, quando se posicionava, arrependia-se, como mostram suas falas:

Puxa vida! Eu tenho que pensar um pouco pra falar, eu fico com a consciência pesada!

Eu falei para elas (amigas) que havia um monte de coisas em promoção. Daí, elas foram e não gostaram de nada e na volta tomaram chuva ainda. Aí eu falei: ai, meu Deus, eu devia ter ficado quieta!

A minha amiga falou assim: aquilo lá não é bom (sobre máquina de lavar louça), aquilo lá demora, eu não tenho vontade de comprar. Eu falei assim: imagina, aquilo é uma maravilha, é ótimo, eu tenho e lavo e a louça fica limpinha (...). Aí, depois, eu fiquei pensando: nossa, eu acabei com o pensamento da outra!

Para evitar brigas eu peço desculpas, mesmo o outro estando errado.

A gente não pode se prejudicar por ter medo de falar e isso acontece muito comigo.

i) Ana mostrou-se muito preocupada quanto à normalidade/anormalidade de seus comportamentos: Gosto de assistir 'A Bela Adormecida', será que é normal? É normal a gente se preocupar (sobre a briga do irmão com o cunhado)? É normal ter mais afinidade com uma amiga do que com 
outra? Este tipo de preocupação poderia ser influência da visão dicotômica apresentada por seu médico psiquiatra, presente em conceitos como saúde/doença, normalidade/ anormalidade.

\section{ANÁLISE FUNCIONAL DO CASO: MULTIDETERMINAÇÃO}

Será apresentada, a seguir, a análise funcional de alguns dos comportamentos que se mostraram relevantes para a compreensão da situação vivenciada pela cliente. Comportamentos apresentados anteriormente por Ana foram incluídos nessa análise porque suas conseqüências contribuem para o entendimento de comportamentos atuais.

A Figura 1 apresenta a análise do comportamento de Ana ao freqüentar um grupo religioso, antes do casamento, quando voltou a viver com seus pais. A partir da análise funcional, observa-se que esse comportamento era reforçado positiva e negativamente: redução de conflitos com o pai, sair com vários outros jovens, participar de festas e aprendizagem de um conjunto de regras de comportamento que, segundo ela, a faziam ser uma pessoa melhor.

A Figura 2 apresenta a análise funcional do comportamento que Ana apresentava no início do casamento e que gerava várias dificuldades em sua interação com o marido: ficar em casa, e a Figura 3 apresenta a análise de outro comportamento que a cliente passou a apresentar na mesma situação, ou seja, acompanhar o marido às reuniões sociais.

O comportamento de Ana descrito na Figura 2 parece revelar uma forma de esquivarse de estimulação aversiva, mas ele próprio gerava também conseqüências aversivas. $O$ comportamento alternativo apresentado por Ana (Figura 3) também era mantido mais por reforço negativo que positivo. Essas duas figuras explicitam uma situação de conflito na qual nenhuma alternativa livre de aversividade parece existir. Análises teóricas têm indicado ser difícil uma pessoa sentir-se bem e feliz nesse tipo de contingência.

A Figura 3 mostra o comportamento de Ana, atualmente, acompanhar o marido às reuniões sociais. Esse comportamento, apesar de ser punido pelo fato de a cliente sentir-se

\section{ANTECEDENTES}

- História de desentendimento e de punição severa, por parte do pai, por sair para divertir-se.

- Morar novamente com os pais.

- Ter passado algum tempo afastada dos antigos amigos.

- Interesse por assuntos religiosos.

- Insatisfação com a religião Católica.

- Oportunidade para conhecer um grupo de estudos bíblicos.

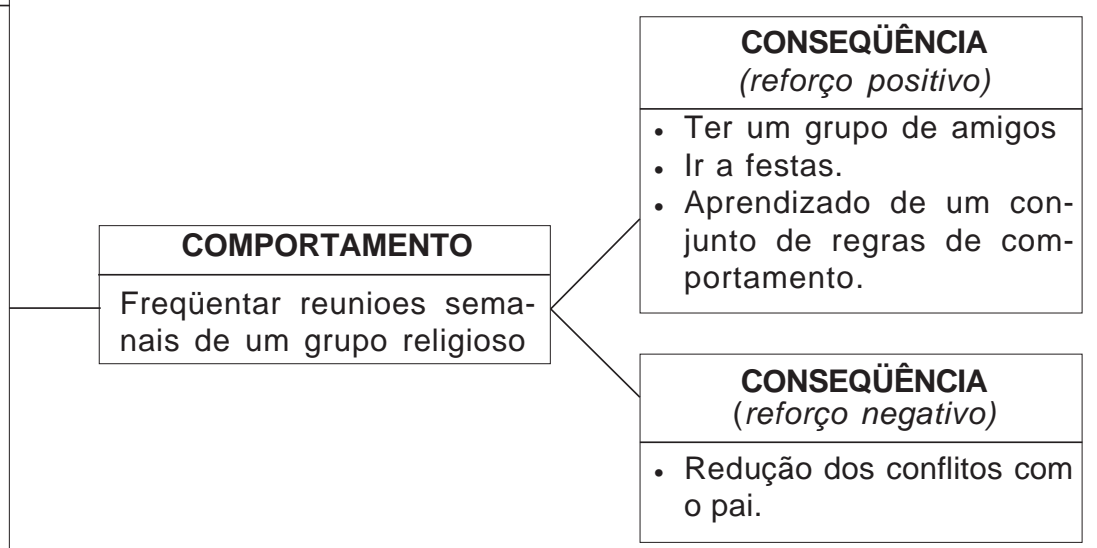

Figura 1. Análise Funcional do comportamento de Ana freqüentar um grupo de estudos bíblicos. 


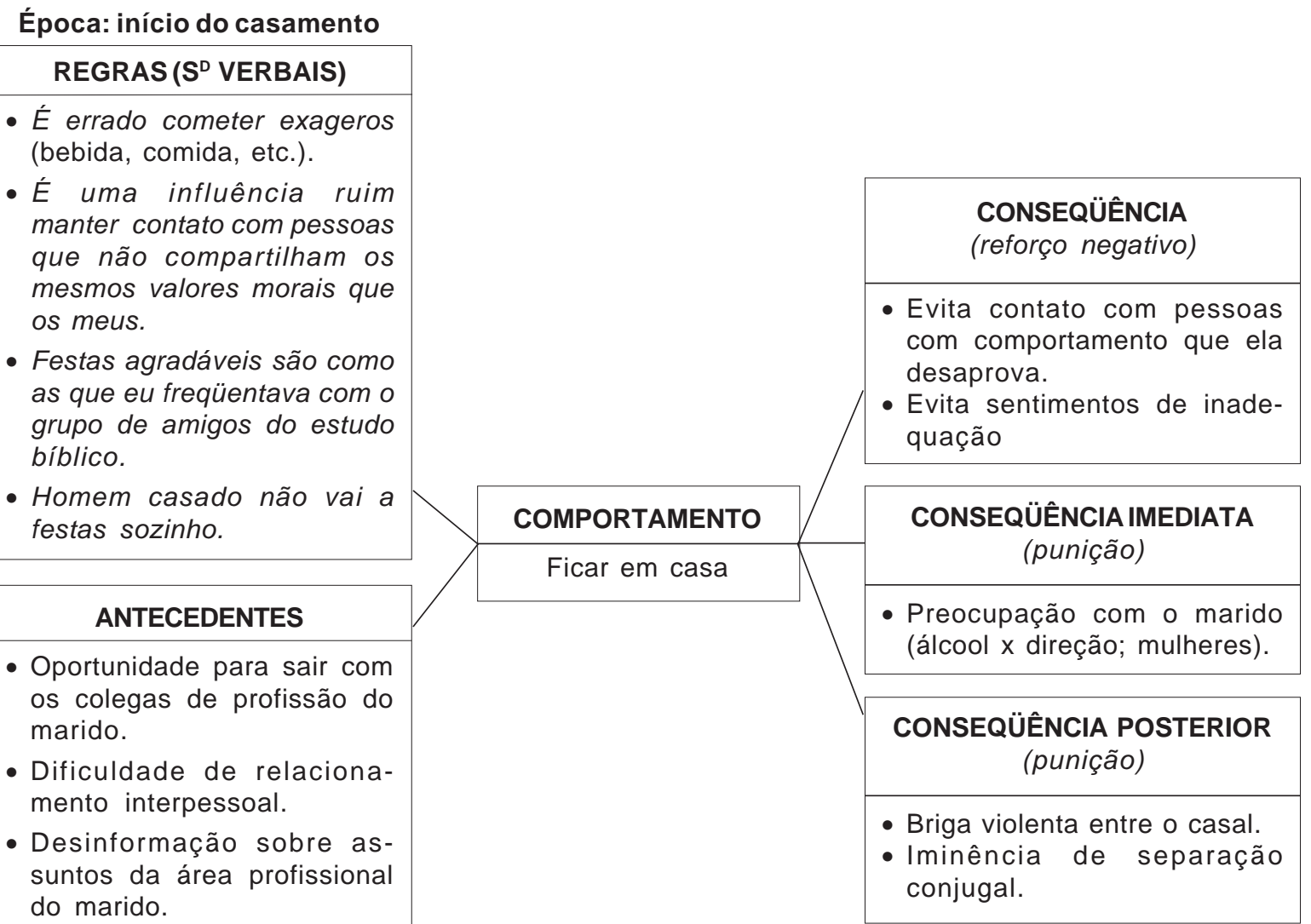

- Medo do marido conhecer outra mulher mais interessante.

- Medo do marido dirigir alcoolizado.

Figura2. Análise Funcional do comportamento de Ana ficar em casa enquanto o marido vai a reuniões sociais.

deslocada nas reuniões, é reforçado por evitar os estímulos aversivos decorrentes de ficar em casa. Acompanhando o marido, ela não fica sozinha, tem a companhia dele, reduz preocupações e diminui os desentendimentos entre eles.

A Figura 4 apresenta um comportamento freqüente na vida conjugal de Ana: brigar com o marido. A análise funcional indica que a cliente possui algumas regras sobre casamento que confrontam com as atitudes do marido, o que propicia o desentendimento entre eles. Algumas vezes, as conseqüências desse comportamento são aversivas; outras, o comportamento é reforçado pelo fato de o marido deixar de sair à noite por alguns dias e realizar alguma atividade doméstica. Essa intermitência contribui para que este comportamento se mantenha.

Outro comportamento freqüentemente apresentado por Ana é o de ficar deitada durante horas; a análise deste fato está apresentada na Figura 5. Comportando-se dessa forma, Ana obtinha certas conseqüências reforçadoras, como preocupação por parte do marido e o auxílio deste e de sua mãe na 
Época: atual

\begin{tabular}{|l|l|}
\hline \multicolumn{1}{|c|}{ REGRAS (SD VERBAIS) } \\
$\begin{array}{l}\text { - É errado cometer exageros } \\
\text { (bebidas, comidas, etc.). } \\
\text { - É uma influência ruim manter } \\
\text { contato com pessoas que } \\
\text { não compartilham os } \\
\text { mesmos valores morais que } \\
\text { os meus. }\end{array}$ \\
- Festas agradáveis são como \\
as que eu freqüentava com o \\
grupo de amigos do estudo \\
bíblico.
\end{tabular}

- Gostar de ficar em casa.

- Medo do marido conhecer outra mulher mais interessante e dele dirigir alcoolizado.

- Experiência anterior de não ter acompanhado o marido, o que foi várias vezes seguido de conseqüências aversivas.

Figura 3. Análise Funcional do comportamento de Ana acompanhar o marido a reuniões sociais.

realização dos serviços domésticos. É importante ressaltar que esse comportamento, muitas vezes visto como decorrente de um estado de humor, denominado depressão, aqui é analisado como decorrente de conseqüências reforçadoras, apresentadas pelo ambiente.

O próximo comportamento analisado é o de Ana emitir opiniões, sugestões e comentários, ou seja, atuar assertivamente. A análise deste comportamento indica que possivelmente a história de punição social precoce, freqüente e intensa, gerada pelos comportamentos de desvalorização e ridicularização por parte do pai e a falta de reforço positivo advindo de outras fontes, contribuiu para que ela avaliasse seus 


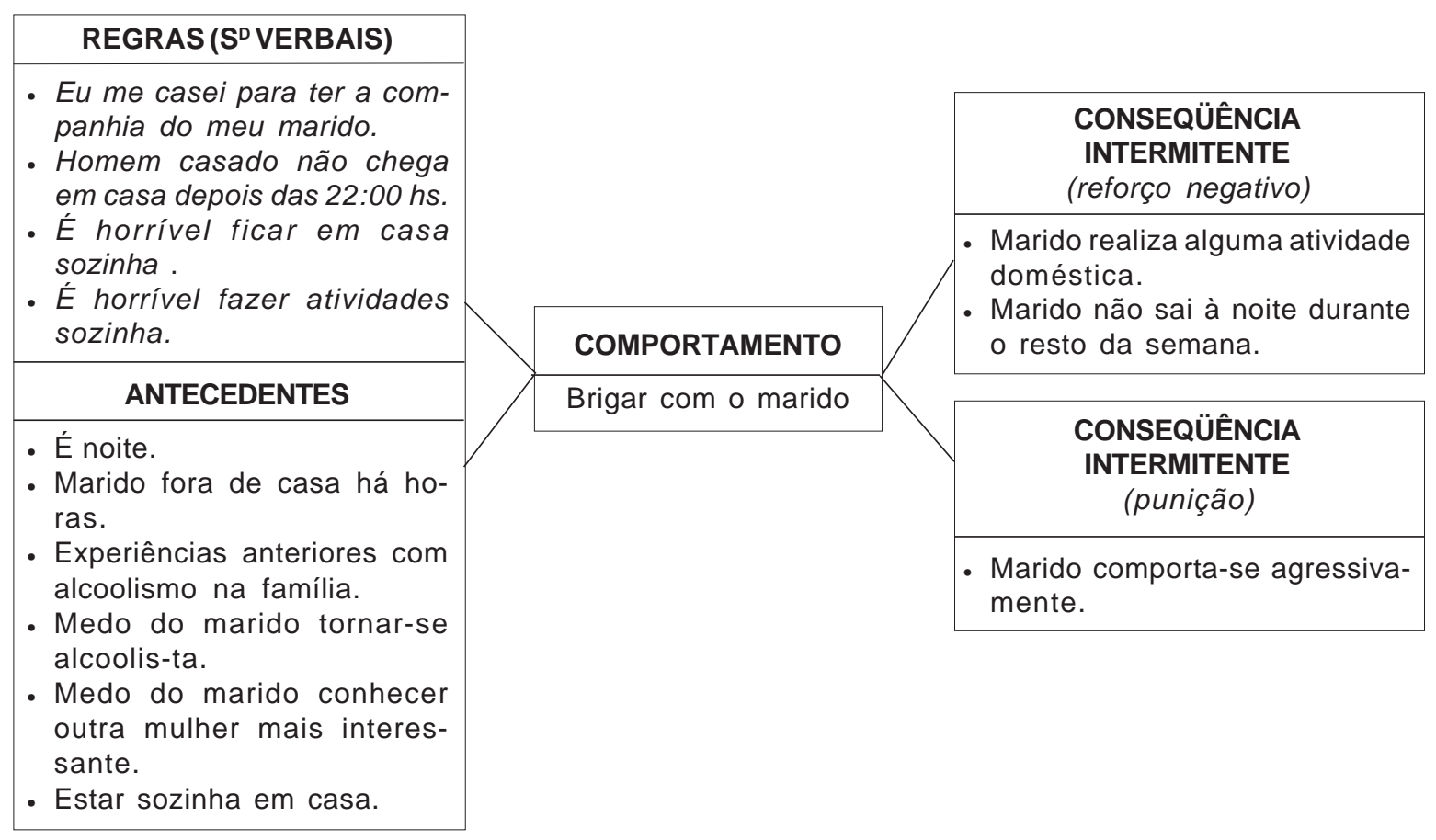

Figura 4. Análise Funcional do comportamento de Ana brigar com o marido, em uma situação específica.

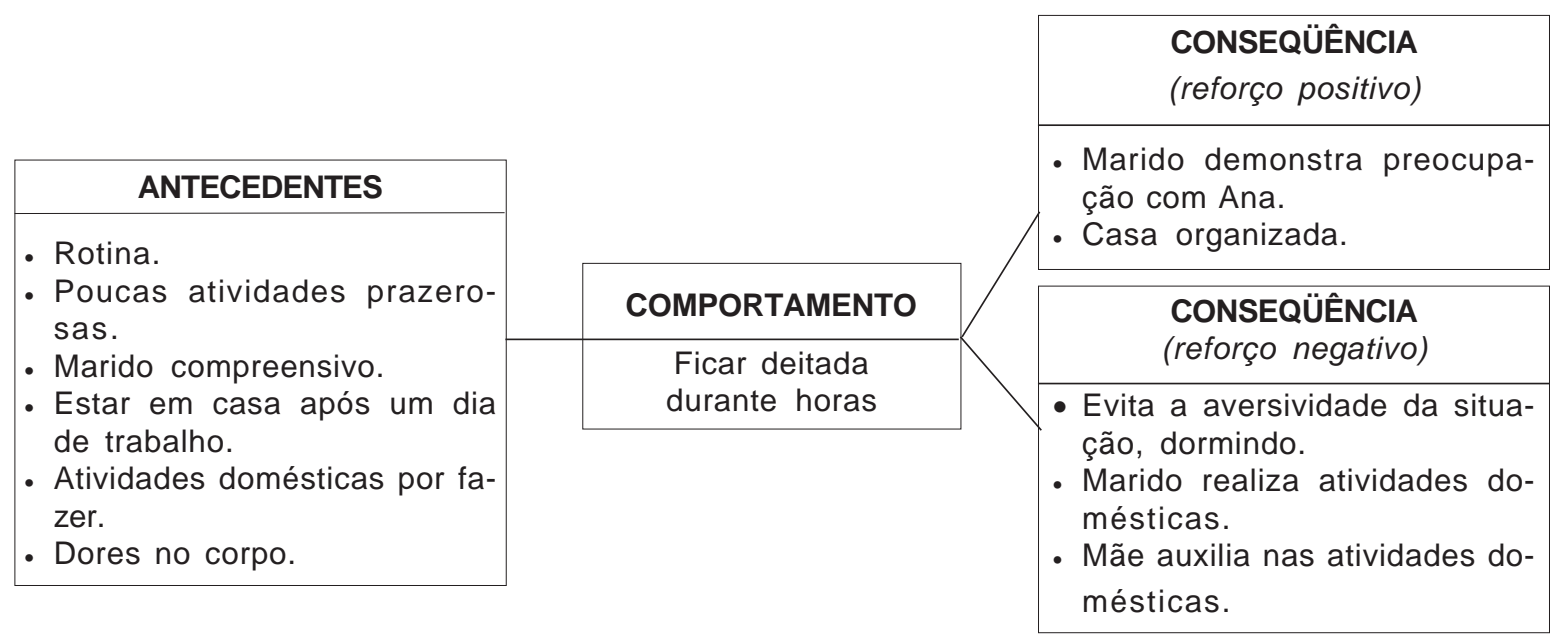

Figura 5. Análise Funcional do comportamento de Ana ficar deitada durante horas quando chega em casa após um dia de trabalho.

comportamentos de emitir opiniões e fazer sugestões como sendo inadequados, mesmo quando não ocorria desaprovação por parte dos demais. Isto gerava estimulação aversiva sob a forma de ansiedade e de sentimento de inadequação. 


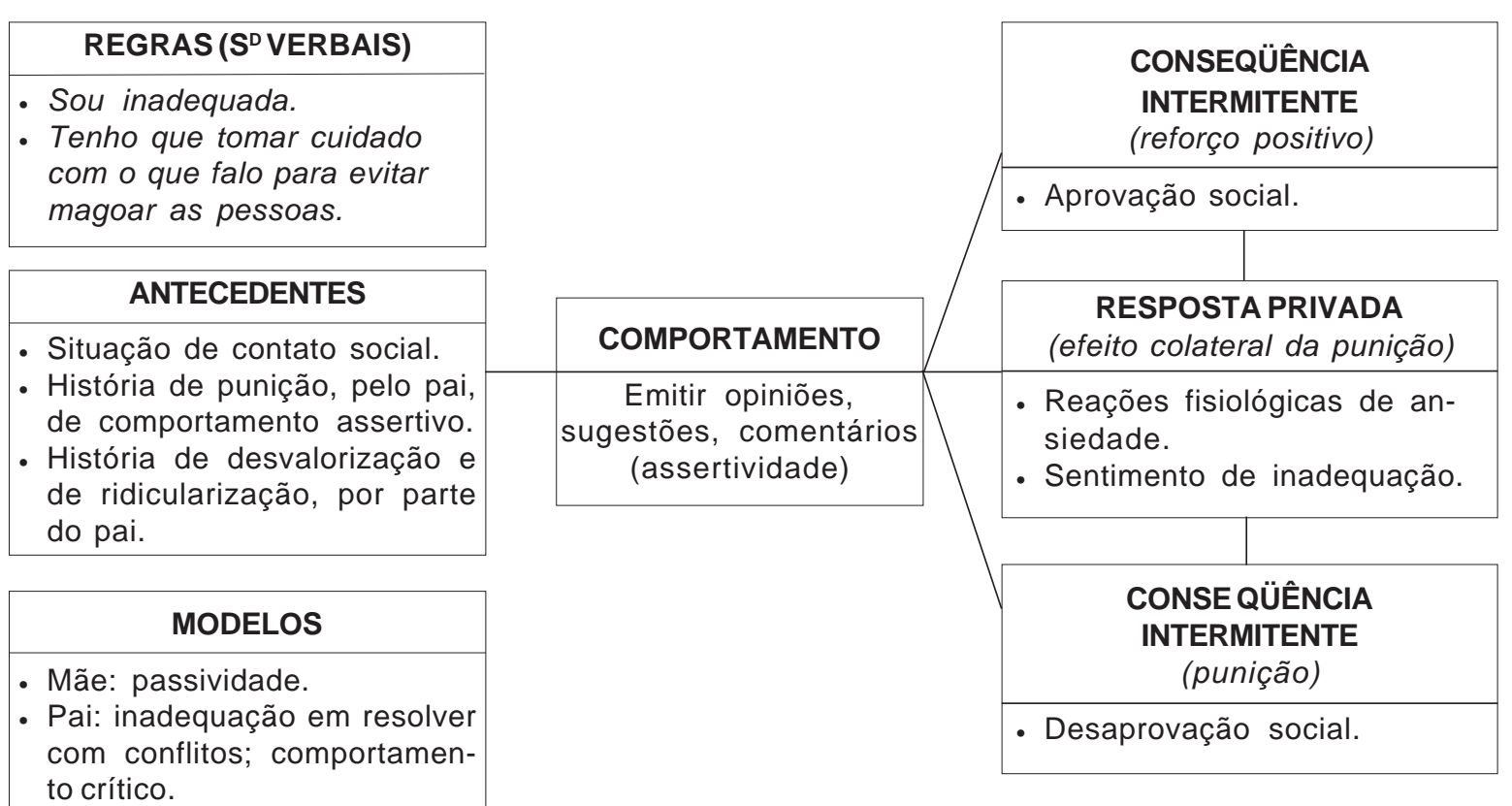

Figura6. Análise Funcional do comportamento de Ana comportar-se assertivamente, emitindo opiniões, sugestões, comentários.

\section{COMENTÁRIOS FINAIS}

Com base nas análises apresentadas, considera-se que, as principais variáveis relacionadas à ocorrência de um conjunto de comportamentos apresentados por Ana e descritos por outros profissionais sob o título único de depressão, parecem ser: perda de reforçadores positivos importantes após se casar; não substituição dos reforçadores perdidos por outros; muitos comportamentos mantidos por reforço negativo. Além disto, com a baixa taxa de respostas apresentadas pela cliente, a probabilidade de obtenção de reforços positivos contingentes ao seu comportamento fica também reduzida.

Essa é uma forma de compreensão do comportamento humano como fruto de interações do indivíduo com seu ambiente. Por meio de análise funcional criteriosa, poder-se-ia perceber que aquele seria o comportamento mais provável de ser apresentado por aquele indivíduo, dadas as contingências envolvidas (Banaco, 1997). As análises funcionais apresentadas são hipóteses para explicação dos comportamentos analisados e são probabilísticas. Hipóteses essas que devem ser confirmadas ou refutadas através da manipulação de variáveis e da observação de seu efeito sobre o comportamento. Ou seja, as intervenções propostas devem, necessariamente, relacionar-se a tentativas de mudanças em variáveis independentes (variáveis funcionais antecedentes ou conseqüentes) de forma a produzir mudanças na variável dependente (comportamento).

\section{REFERÊNCIAS BIBLIOGRÁFICAS}

BAER, D. M.; Wolf, M. M. e Risley, T. R. (1968). Some current dimensions of applied behavior analysis. Journal of Applied Behavior Analysis, 1, 91-97.

BANACO, R. A. (1997). Auto-regras e patologia comportamental. Em: D. R. Zamignani 
(org.), Sobre comportamento e cognição. Santo André: Arbytes.

CARR, E. G.; Langdon, N. A. e Yarbrough, S. C. (2000). La intervención basada en hipótesis para tratar conductas problema severas. Em: A. C. Reep e R. H. Horner, Análisis funcional de problemas de la conducta. Madrid: Paraninfo, pp. 9-29.

FERSTER, C. B. (1973). A functional analysis of depression. American Psychologist, 28, 857-870.

GOLDIAMOND, I. (1975). Alternate sets as a framework for behavioral formulation and research. Behaviorism, 3, 49-86.

GRESSWELL, D. M. e Hollin, C. R. (1992). Toward a new methodology of making sense of case material: an illustrative case involving attempted multiple murder. Clinical behaviour and mental health, 2, 329-341.
HAYNES, S. N. e O'Brien, W. H. (1990). Functional analysis in behavior therapy. Clinical Psychology Review, 10, 649-668.

IWATA, B. A., Vollmer, T. E. e Zarcone, J. R. (1990). The experimental (functional) analysis of behavior disorders: Methodology, application and limitations. Em: A. C. Repp e N. N. Singh (org.), Perspectives on the use of non-aversive and aversive interventions for persons with developmental disabilities (pp.301-330). Sycamore, IL: Sycamore Publications.

SKINNER, B. F. (1953). Science and human behavior. New York: Macmillan.

SKINNER, B. F. (1975). Contingências de reforço: uma análise teórica. Coleção Os Pensadores, volume 51.

STURMEY, P. (1996). Functional analysis in clinical psychology. Chichester: John Wiley \& Sons. 